\title{
Gene Expression Profiles of Rodent Atrophic Gastritis Induced By Hot and Salt Water
}

Junrong $\mathrm{Xu}^{1}$, Li Zhang ${ }^{1 *}$, Lingxia Zhang ${ }^{1}$, Kan Wang ${ }^{2}$, Jun $\mathrm{Chen}^{2}$, Changhe Jia ${ }^{1}$, Lili Feng ${ }^{2}$, Daxiang Cui ${ }^{2,3}$.

\begin{abstract}
${ }^{1}$ Department of gastroenterology of Xian Central hospital, Xi'an, 71003, P.R. China
Department of Bio-Nano Science and Engineering, Key Laboratory for Thin Film and Microfabrication Technology of Ministry of Education, National Key Laboratory of Micro/Nano Fabrication Technology, Institute of Micro/Nano Science and Technology, Shanghai Jiaotong University, 800dongchuan Road, Shanghai 200240, P. R. China

${ }^{3}$ Institute of Genetic Diagnosis of Fourth Military Medical University, Xian, 710032, P.R. China
\end{abstract}

Corresponding authors: xujunrong@netease.com (Li Zhang ) and dxcui@sjtu.edu.cn (DaxiangCui)

\begin{abstract}
Diet factors may be potential causes for atrophic gastritis. This study is to establish rat atrophic gastritis models under various hot and salt water conditions and to explore the associated molecular mechanisms. $96 \mathrm{SD}$ rats were divided randomly into 4 experimental groups and used to establish atrophic gastritis models. 2 rats from each group were sacrificed every other week to collect gastric sinus tissues for pathological analysis. When atrophic lesion was identified in a given group, all remaining rats in that group were sacrificed and gastric sinus tissues were collected. The cDNA probes from sinus atrophic lesion or control sinus mucous were labeled with Cy5 or Cy3, respectively. These probes were mixed and hybridized with cDNA microarrays. Hot salt water group was pathologically confirmed to exhibit atrophic lesion in 10 weeks. Salt water group and hot water group were confirmed to exhibit atrophic lesion in 24 weeks. The atrophic lesions located mainly in gastric sinus. 288 differentially expressed genes were identified between hot salt water group and normal control group. 162 differentially expressed genes were identified between hot water group and normal control group. 81 differentially expressed genes were identified between hot salt water group and salt water group. In conclusion, rat atrophic gastritis models induced by various hot and salt water conditions have been established. The corresponding gene expression profiles have been firstly established. This study shows that dietary factors such as temperature and salt concentration may play an important role in the development of atrophic gastritis.
\end{abstract}

Keywords: rat, atrophic gastritis model, gene expression profiling, cDNA microarrays, hybridization

Citation: J. Xu, et al. Gene Expression Profiles of Rodent Atrophic Gastritis Induced By Hot and Salt Water. Nano Biomed. Eng. 2011, 3(4), 236- 242. DOI: 10.5101/nbe.v3i4.p236-242.

\section{Introduction}

Gastric cancer was once the second most common cancer in the world [1]. Up to date, in the United States, stomach malignancy is currently the 14 th most common cancer, and 2th most common cancer in China [2]. Gastric cancer is still the second most common cause of cancerrelated death in the world, and remains difficult to cure because most patients present with advanced disease. Therefore, how to prevent early gastric cancer is a great challengeable task. It is well known that atrophic gastritis finally results in gastric cancer formation. To clarify the potential risk factors and potential mechanism of atrophic gastritis will be helpful to prevent gastric cancer.

Atrophic gastritis is a precancerous lesion with the highest rate of incidence among human gastric intestinal diseases and plays a key role in the initiation of gastric cancer [3]. Some genes and proteins have been confirmed to be closely associated with the progression of atrophic gastritis [4-6]. However, the molecular mechanism of normal gastric mucous gradually evolving into atrophic lesion is still unclear, although infection such as helicobacter pylori infection, is partially considered to be direct cause of atrophic gastritis [7]. The role of dietary factors such as temperature and salt concentration of food in progression of gastric atrophic lesion has not been investigated.

Biological microarray techniques have the advantage of simultaneously monitoring the expression of thousands of genes in one hybridization experiment [8]. 
These techniques have greatly facilitated detection of differentially expressed genes and construction of gene expression profiles. Since 1995, the DNA microarray technique has been widely employed to investigate function of genes, especially those genes involved in disease generation and growth $[9,10]$. This technique has great potential as a practical clinical tool for medical diagnosis. As part of the preliminary effort to establish a prewarning data library of early gastric cancer based on biological microarrays and CAD technology [11,12], we have been screening and cloning differentially expressed genes between precancerous lesion and gastric cancer, and also designed and prepared nanoprobes to find early in situ gastric cancer, with the aim of establishing a gastric cancer prewarning system [13-22]. The present study is a coherent part of our overall activities on molecular mechanism of gastric diseases including gastritis, precancerous lesion and carcinoma.

In this study, we established rat models of atrophic gastritis induced by water with high temperature and high salt concentration. Lesion gastric sinus tissues and normal gastric sinus tissues are collected and screened for differentially expressed genes between them using high density mouse cDNA microarrays. Our aim is to explore the molecular mechanism of atrophic gastritis induced by high temperature and salt concentration, and to lay foundation for development of diagnosis techniques of early gastric cancer.

\section{Experimental Section}

\subsection{Materials source}

$96 \mathrm{SD}$ rats with 200-250 g of weight, 7 weeks of age, male maturation and no H.pylori infection were provided by Animal Experiment Center of Fourth Military Medical University. All procedures were approved by the Institutional Animal Care Committee of University. The extraction kit of mRNA was polyATtract system 1000 kit from Promega Company; the kit for reverse transcription was from Clontech Company; Cy3-dUTP and Cy5-dUTP were from Pharmacia Company; high density microarrays with 8,000 cDNA sites (M80S) were from Shanghai BioStar Genechip Inc. which provides the cDNA names and sequences at the website http://www.chinagenenet.com.

\subsection{Atrophic gastritis models}

The 96 healthy SD rats were randomly divided into 4 groups consisting of normal control group (fed with $25^{\circ} \mathrm{C}$ water, $2.5 \mathrm{ml}$ per day), salt water group (fed with $25^{\circ} \mathrm{C}$, $150 \mathrm{~g} \mathrm{~L}^{-1}$ sodium chloride, $2.5 \mathrm{ml}$ per day), hot water group (fed with $55{ }^{\circ} \mathrm{C}$ water, $2.5 \mathrm{ml}$ per day), hot salt water group (fed with $55{ }^{\circ} \mathrm{C} 150 \mathrm{~g} \mathrm{~L}^{-1}$ sodium chloride, $2.5 \mathrm{ml}$ per time, 2 times per day). 24 rats in each group were placed in cages with constant temperature of $24^{\circ} \mathrm{C}$, humidity of $50-60 \%$. At the beginning of experiments,
1 rat in the normal control group was sacrificed, with gastric tissues collected and kept in liquid nitrogen for control. 2 rats from each group were sacrificed every 2 weeks and gastric sinus mucous tissues were subject to pathological analysis. When atrophic lesion in each experiment group is identified, all remaining rats in that group were sacrificed, and gastric sinus mucous tissues were collected and kept in liquid nitrogen. Atrophic gastritis was diagnosed according to the international standard in the literature $[23,24]$.

\subsection{Extraction of mRNAs and probe preparation}

Messenger RNA extraction is performed using polyATtract system 1000 kit from Promega Inc. Gastric sinus mucous tissues were stored in liquid $\mathrm{N}_{2}$, ground into tiny granules in $100 \mathrm{~mm}$ ceramic mortar (RNase free) and homogenized in Solution D containing $1 \%$ mercaptoethanol. The remaining procedure was performed according to manufacturer's instructions. Final mRNA templates were dissolved in RNAse-free $\mathrm{H}_{2} \mathrm{O}$. Fluorescent cDNA probes were prepared through reverse transcription and purified according to the literature [25, 26]. The probes from different experiment groups were labeled with Cy5-dUTP, and those from normal control group and salt water control group were labeled with Cy3-dUTP. The labeled probes were purified, mixed, fragmented and precipitated by ethanol, and finally dissolved in $20 \mu \mathrm{l}$ hybridization solution.

\subsection{Hybridization and washing}

After denaturing at $95^{\circ} \mathrm{C}$ for 5 minutes, the probes were added onto slides, covered with a cover glass and incubated at $42^{\circ} \mathrm{C}$ for 17 hours. The slides were subsequently washed in solutions of $2 \times \mathrm{xSC}+0.2 \% \mathrm{SDS}$, $0.1 \mathrm{xSSC}+0.2 \%$ SDS and $0.1 \mathrm{xSSC}, 10$ minutes each time, and then dried at room temperature.

\subsection{Detection and analysis}

Affymetrix $428^{\mathrm{TM}}$ Array Scanner was used for chip screening. The acquired images were quantified, corrected for background noise and normalized. ImageGene 3.0 Software (BioDiscovery Inc.) was used for quantitative analysis. The experiments based on microarrays screening were repeated for 3 times. The average value of each gene expression level was analyzed. Cut-off value of differentially expressed genes was set to \pm 2.5 for ratio.

\subsection{Statistical Analysis}

Two-way clustering and Tree View analyses were performed using Cluster Software and Tree View software from Stanford university. The statistical analysis of significant difference was performed using the $t$ test. All $p$ values are based on two-sided testing, and a significant difference was defined as less than 0.05 . 
http://nanobe.org

\section{Results}

\subsection{Establishment of rat atrophic gastritis models}

Rats from the hot salt water group were confirmed to have developed typical gastric atrophic lesion in 10 weeks (Fig. 1A), these lesions mainly located in gastric antrum and gastric body, the mucous layer became thin and the underneath smooth muscles showed clear hyperplasia. At 24 weeks, rats from the salt water group and the hot water group were confirmed to have typical gastric atrophic lesions in gastric antrum (Fig. 1B, Fig. 1C). No remarkable proliferation of fiber connective tissues in mucous intrinsic layer and mucous muscle layer were not found, inflammatory cell invasion and blood angiectasis also were not remarkable, the width of mucous muscle layer is narrower compared with lesion in hot salt water

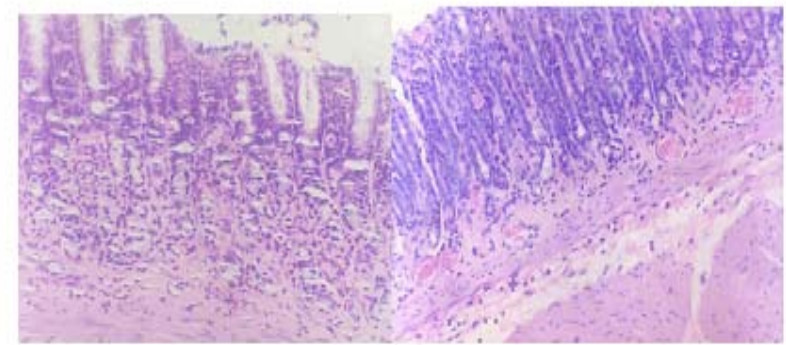

Fig.1A1 hot salt water group x 200 of typical atrophic lesion (in 10weeks). Atrophic lesion in gastric corpus, the mucous layer becomes thin and the underneath smooth muscles show clear hyperplasia. Fig.1A2 trophic lesion in gastric sinus.

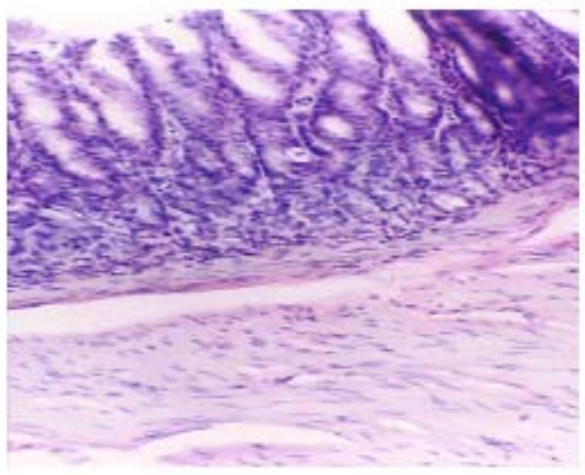

Fig.1B Hot water group x 200 of slight atrophic lesion (in 24 weeks)

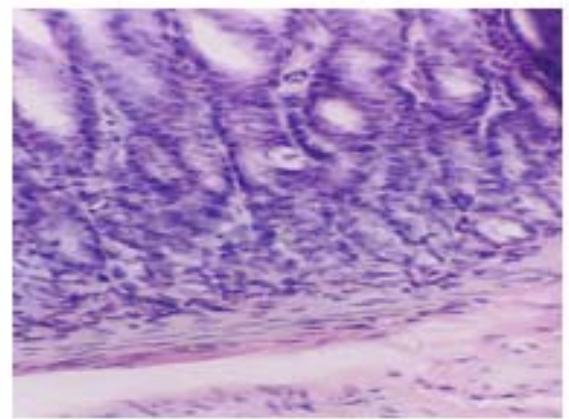

Fig.1C Salt water group x 200 of slight atrophic lesion (in 24 weeks)

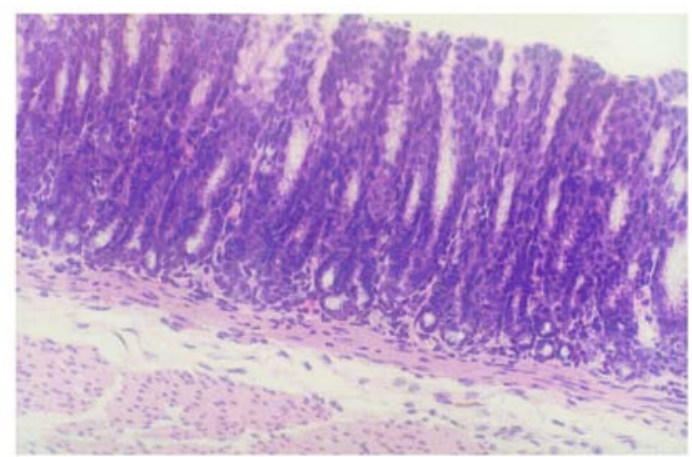

Fig. 2 Control group x 200 of normal mucous tissue. The smooth mucous surface shows no erosion, no inflammatory cells invasion into the intrinsic layer, no edema in mucous underlayer and no inflammatory cells invasion into the muscle layer.

group. No special histopathological features were found to be closely associated with atrophic gastritis induced by hot and salt water. No atrophic lesion was observed in normal control group (Fig. 2).

\subsection{Differentially expressed genes between hot water group and normal control group}

Using normal gastric sinus mucous as control, the microarray hybridization result of sinus atrophic lesion

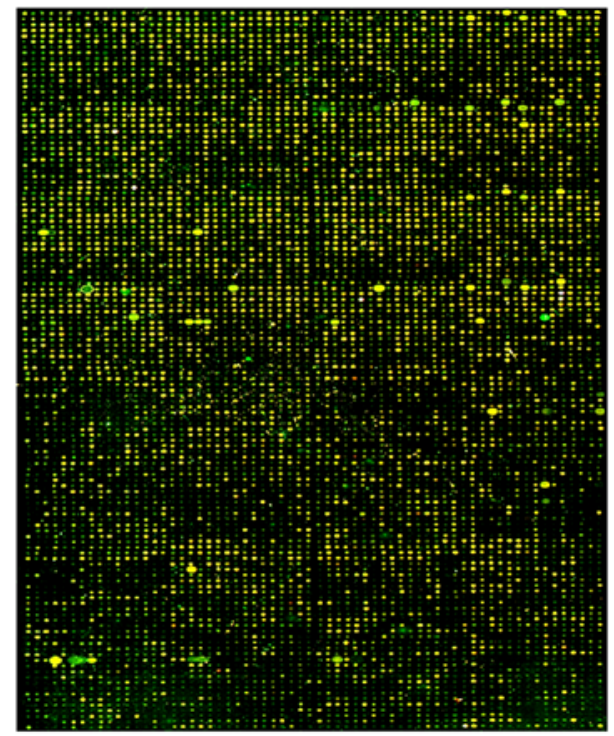

Fig.3 Hybridization result of the hot water group (supporting information)

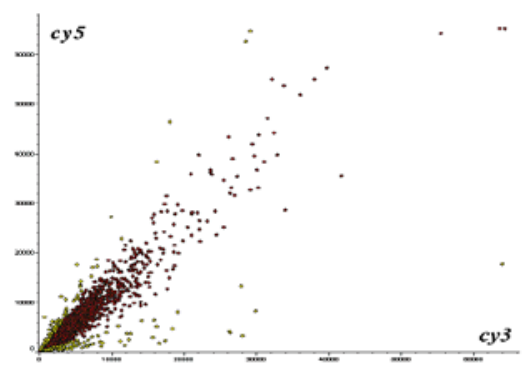

Fig.4 Scatter plot of differentially expressed genes in the hot water group

Nano Biomed. Eng. 2011, 3(4), 236-242 
mucous from the hot water group at 24 weeks was shown in Fig. 3 in supporting information. According to the screening standard of differentially expressed genes, 162 genes were differentially expressed, among which 30 genes exhibited higher expression in sinus atrophic lesion than in normal sinus control, 132 genes exhibited higher expression in normal sinus tissues than in atrophic sinus tissues. Scatter analysis plot of differentially expressed genes was in Fig. 4. The differentially expressed

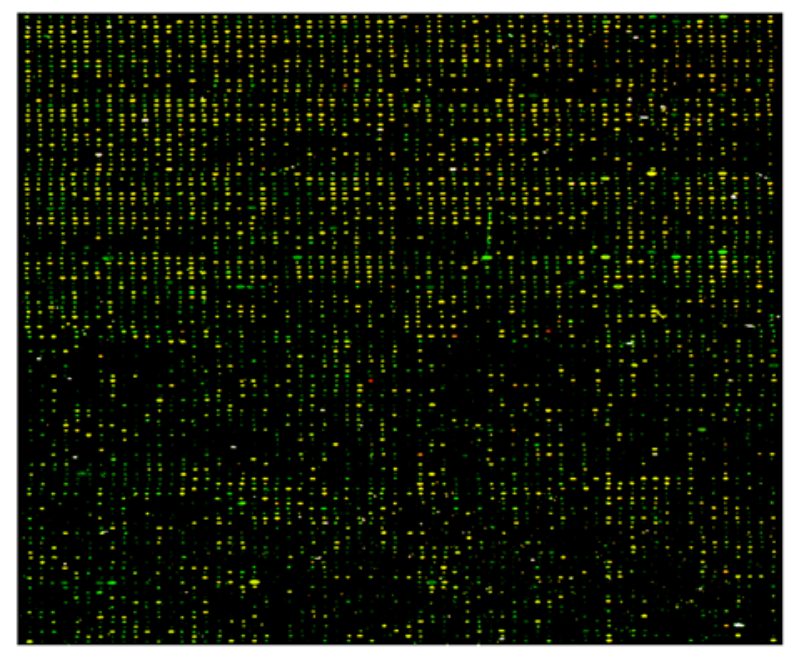

Fig.5 Hybridization analysis result of hot salt group (supporting information)

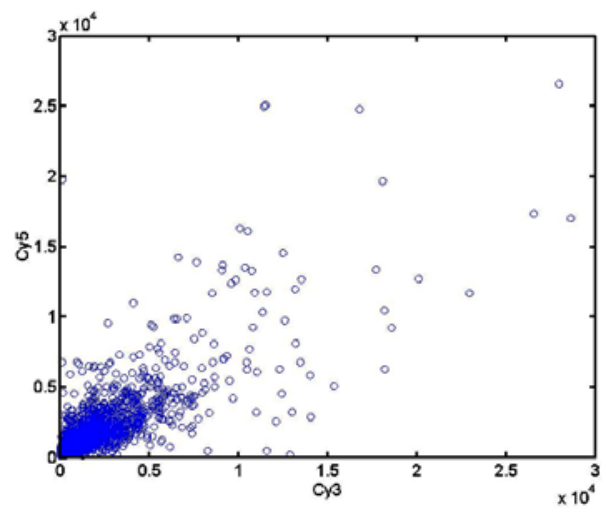

Fig.6 Scatter analysis plot of hot salt group

genes were summarized in Table S1(see Supporting Information).

\subsection{Differentially expressed genes between hot salt group and normal control group}

Using normal gastric sinus mucous as control, the microarray hybridization result of sinus atrophic lesion mucous from the hot salt water group at 10 weeks was shown in Fig. 5 in supporting information. 288 genes were differentially expressed, among which 100 genes exhibited higher expression in sinus atrophic lesion than in normal sinus control, 188 genes exhibited higher expression in normal sinus tissues than in atrophic sinus tissues. Scatter analysis plot of differentially expressed genes was in Fig. 6. Differentially expressed genes was Nano Biomed. Eng. 2011, 3(4), 236-242 http://nanobe.org

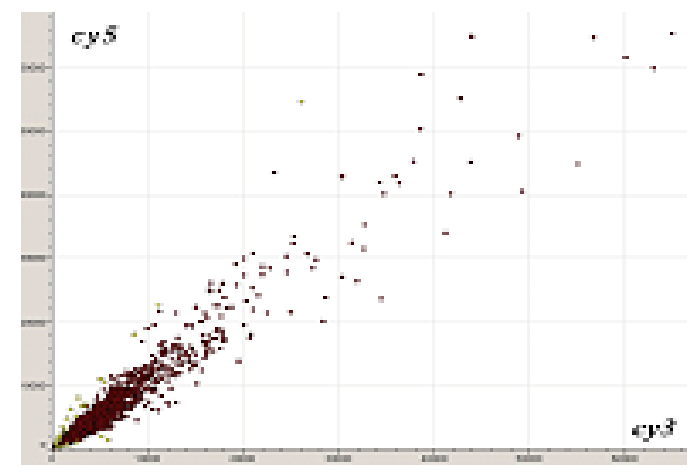

Fig.7 Scatter plot of differential gene expression between hot salt water group and salt water group.

summarized in Table S2 (see Supporting Information).

\subsection{Differentially expressed genes between hot salt group and salt water control group}

Using the atrophic sinus lesion from salt water group at 24 weeks as control, the microarray hybridization result of atrophic sinus lesion from the hot salt water group at 10 weeks was obtained. 81 genes were mainly differentially expressed between experiment group and control group, among which 57 exhibited higher expression in the sinus tissues from hot salt water group than in the tissues from salt water group, 24 exhibited higher expression in the sinus tissues from salt water control than in the tissues from hot salt water group. scatter plot of differentially expressed genes was in Fig. 7. The list of genes and Genbank No. were summarized in Table s3(see Supporting Information).

\section{Discussion}

Chronic atrophic gastritis is the most common gastric precancerous lesion. Presently, atrophic gastritis is considered an autoimmune gastropathy in which there is destruction of gastric parietal cells [27,28]. This results in intrinsic factor deficiency, disturbance in vitamin B12 absorption and a reduction in basal acid output. Multifocal atrophic gastritis (MAG) is currently considered a precancerous lesion leading to intestinal type gastric carcinoma [29]. Up to now, atrophic gastritis is widely regarded as a direct result of the Helicobacter pylori infection because $H$. pylori infection triggers an autoimmune gastritis of the corpus mucosa, leading to atrophy and intestinal metaplasia [26-28]. The presence of antibodies to CagA or VacA seems to be associated with the development of atrophic corpus gastritis. $H$. pylori gastritis also triggers a variety of reaction cascades resulting in errors of the cell genome and ending up as tumors. Aging and smoking are also known to promote atrophic gastritis (AG) [30-32].

Chronic atrophic gastritis (CAG) is the key stage in OChOST 239 
the course of gastric carcinogenesis. Gastric carcinoma develops in CAG through stages of hyperplasia and dysplasia involving both metaplastic and non-metaplastic glands. Molecular alterations, including replication error and p53 and APC gene mutation and aneuploidy have been found in some of these lesions [33]. p53, iNOS and VEGF positive immunostaining were observed in the tissues with different severities of lesions of chronic atrophic gastritis (CAG), intestinal metaplasia (IM) and dysplasia (DYS), and the positive rates increased with the lesion progression from CAG to IM to DYS. Furthermore, MUC1 and expression level of telomerase have been linked to atrophic gastric lesion [34-36].

However, the molecular mechanism of atrophic gastritis remains unclear. It is well known that many genes participate in the course of progression of atrophic gastritis. Finding out these genes are helpful to clarify the molecular mechanism of atrophic gastritis. Establishing animal atrophic gastritis model is an important method to clarify the mechanism of atrophic gastritis. Up to now, there are many methods used to establish animal atrophic gastritis model [37-40]. In our research, rat atrophic gastritis models are developed to investigate the effects of temperature and salt concentration. The results exhibited that hot salt water may cause rat gastric antrum mucous and body mucous atrophy in 10 weeks. Within this time period, normal group, hot water group and salt water group didn't show signs of atrophic lesion. In 24 weeks, rat gastric mucous of antrum and corpus from the hot water group and the salt water group also showed atrophic lesions, demonstrating that hot water or salt water alone can also cause atrophy of gastric mucous. These results also indicate that high temperature and salt concentration may work together to accelerate the initiation of gastric mucous atrophy.

Based on this study, to explore the molecular mechanism of atrophic gastritis, we have used rat cDNA microarrays with 8,000 genes to establish gene expression profiling of atrophic gastric sinus mucous induced under different hot and salt water conditions. Rat and mouse are attributed to rodents, so their gene sequences have highly homologous, these homologous cDNA probes are designed, synthesized and spotted on the substrates of microarrays. We repeated the experiments based on microarrays screening for 3 times, the average values of gene expression level were analyzed. These results show that in the atrophic lesion of gastric antrum caused by hot salt water, there existed many differentially expressed genes such as ras, prion protein-like protein gene, YNL gene, chemokine (C-X-C) receptor 2, testis specific gene1, Slc4a1gene, megakaryocyte stimulating factor precursor, Spp1, GAPIII, kif3c, papss2, akap3, M-protein, crcp, KIP, semcap3, ras effector Nore1, calbindin$28 \mathrm{k}$, beta-2-glycoprotein 1, ubiquitous nuclear protein, SULT2B,CML5, Cnt2, ERp72, BMP4, fibroblast growth factor regulated protein, inhibitor of DNA binding 2, immunoglobulin J chain mRNA, etc. Among these genes, 240 some genes are associated closely with immune system, this result demonstrates that immune system also take part in the course of atrophic lesion caused by hot salt water. Further analysis demonstrates that immune system also participate in the course of atrophic gastritis caused by hot water, salt water and hot salt water. Some genes such as ATPase, $\mathrm{H}+/ \mathrm{K}+$ exchanging $\alpha$ polypeptide, Cathepsin E, Gastric lipase, Mucin 6, etc. are associated with gastric digestion, some genes such as Cytochrome P450, Metallothionein E, etc. are associated with detoxification, some genes such as Galectin 9, pancreatitis associated protein,etc. are associated with cell adhesion, some genes such as FGF receptor, trithorax homolog, regenerating protein, etc. are associated with cell proliferation, some genes such as HOX A1, Oct 3, eyes absent (Drosophila) homolog 1 , etc. are associated with development, some genes such as matrix metalloproteinase 3, procollagen C-endopepidace enhancer, protease, etc. are associated with extracellular matrix remoldeling, the remaining genes are associated with cell cycle, cell motility, cytoskeletal, angiogenesis, signal transduction, cell apoptosis, cell metabolism, ion channel and transporting, DNA synthesis and transcription, et c. An interesting phenomena, ras or ras associated genes exhibited higher expression level in every group of atrophic gastritis induced by hot and salt water. Ras gene is an oncogene, which may induce normal cell transfer into cancerous prone cell, its higher expression level in atrophic lesion is likely a characteristic marker associated closely with atrophic lesion, can be used to distinguish normal gastric mucous from gastric atrophic lesion. Our analysis demonstrated, the development of atrophic gastritis is a complex process in which many genes participate and act cooperatively. Water with various high temperature and high salt concentration conditions can all induce gastric atrophic lesion.

However, there are also clear differences in the molecular mechanism of atrophic lesion when conditions change. Different time duration is required for the development of gastric atrophic lesion in rats fed with hot water, salt water and hot salt water. Relatively few (i.e. 81) genes such as adenosine deaminase, ATPase $(\mathrm{Na}+/ \mathrm{K}+$ transporting, beta 1 polypeptide), Mouse germline $\mathrm{IgH}$ chain gene, CXCR2, PLC-L2, SRG, etc.are differentially expressed between hot salt water group and salt water group, suggesting partially shared molecular mechanisms among atrophic lesions induced by hot water, salt water and hot salt water.

Based on the study, we believe that atrophic gastritis may be caused by many factors. For example, diet factor, H. pylori infection etc. H. pylori infection is an important factor to result in atrophic gastritis, twothirds of patients with chronic atrophic gastritis have proofs infected with H.pylori $[41,42]$. H. pylori can also induce gastric atrophic lesion in Mongolian gerbils in 6 months and gastric cancer in 18 months [43]. Sipponen P. et al thought that atrophic gastritis is a direct result 
of the H.pylori infection, H.pylori gastritis triggers a variety of reactions, with the reaction cascades resulting in errors of the cell genome and ending up as neoplastic tumors [17,42]. In fact, chronic atrophic gastritis of high incidence in Helicobacter pylori infection has not been clearly pathogenically explained yet [43-45], its concrete mechanism is still unclarified.

Temperature and salt concentrate in daily food intake are basic factors, are closely associated with diet habits. Higher temperature and higher salt concentrate may induce atrophy gastritis, therefore, habits of intaken hot food and higher salt food should be responsible for atrophic gastritis without H.pylori infection. According to investigation, European diet habit is better than Asian, failure to discern diet and family history as risk factors for ACG because diet is homogenous in Europe [46]. However, we think that diet factors and habits may be closely associated with atrophic lesion. Atrophic gastritis induced by $H$. pylori infection may be based on diet factors, may be a result of acting cooperatively with diet factors.

However, compared with the gene expression profiling differences of atrophic lesions induced by H.pylori, the difference between them was very significant $[47,48]$. H. pylori infection doesn't exist in all atrophic gastritis tissues. According to statistical data, on average twothirds patients of atrophy lesion have been infected with H.pylori [28], and the remaining one-thirds patients are not linked to $H$. pylori infection. It is thus possible that dietary factors such as food temperature and salt concentration play an important part in atrophy lesion. It has also been reported that eradication of $H$. pylori cannot decrease the rate of incidence of gastric atrophic lesion,although abolishing or alleviating some symptom $[49,50]$. Therefore, $H$. pylori is an important but not the sole factor associated with atrophy lesion and gastric cancer. Dietary factors seem to be closely associated with gastric atrophy lesion and can act together with H.pylori infection in the course of the disease. In order to prevent progression of atrophy gastritis, more attention should be paid to dietary habit as well as eradication of $H$. pylori infection. The present study demonstrates that dietary factors can induce gastric atrophy lesion even in the absence of $H$. pylori infection.

\section{Conclusion}

The present study shows that hot water, salt water and hot salt water could induce normal gastric mucous appear atrophic gastric lesion in rats in the absence of $H$. pylori infection. Atrophic gastritis involves a complex course of initiation and development, with many genes participating and acting cooperatively in the development and progression of atrophic lesion. Although significant differences exist between the molecular mechanisms of atrophic lesion induced by hot water, salt water and hot salt water, commonalities also abound. Dietary factors Nano Biomed. Eng. 2011, 3(4), 236-242 such as high food temperature and salt concentration can also trigger gastric atrophy lesion. Further work will focus on confirming and clarifying the functions of those genes associated with atrophy gastritis in near future.

\section{Acknowledgements}

This work was supported by Chinese foundamental basic research Project (2010CB933901and 2011CB933100), 863 Key Project (2007AA022004), New Century Excellent Talent of Ministry of Education of China(NCET-08-0350 and No.20070248050), Special Infection Diseases Key Project of China (2009ZX10004-311), Shanghai Science and Technology Fund (10XD1406100 and 1052nm04100). Authors are grateful to prof. Huajian Gao of Max Planck Institute for critical review and revision of the manuscript.

\section{References}

1. Bondy M. Cancer epidemiology and prevention. JAMA. 2009; 301:1074-1075.http://dx.doi.org/10.1001/jama.2009.270

2. Jemal A, Siegel R, Ward E, Hao Y, Xu J, Murray T, et al. Cancer statistics. CA Cancer J Clin. 2008;58:71-96.http://dx.doi.org/10.3322/ CA.2007.0010

3. Shao JS, Carmel R, Alpers D H. Production of Ectopic Gastric Intrinsic Factor in Gastric Mucosa of Humans with Chronic Gastritis. Digestive Diseases and Sciences.2011;56:3209-3219. http://dx.doi.org/10.1007/s10620-011-1738-3

4. Cui D, Yan, X, Wang F, Su C: New strategy of cloning differentially expressed genes. Prog. Biochem. Biophys. 2000;27:362-364.

5.Cui D, Yan, Wang F, Su C: Studies on differentially expressed genes of gastric cancer by mRNA differential display. Prog. Biochem. Biophys. 2000;27: 379-382.

6 Vitale G, Barbaro F, Ianiro G, Cesario V, Gasbarrini G, Franceschi $\mathrm{F}$, et al. Nutritional aspects of Helicobacter pylori infection. Minerva gastroenterologica e dietologica.2011;57:369-77.

7. Hedenbro JL, Benoni C, Schalen C, Wadstrom T, Guruge JL, Willen R, Floren C. Helicobacter pylori and atrophic gastritis. Tokai. J Exp Clin Med. 1992;17(1):1-4.

8. De RS, Penland JL, Brown PO, Bittner ML, et al. Use of a cDNA microarray to analyze gene expression patterns in human cancer. Nat.' Genet. 1996;14:457-460.http://dx.doi.org/10.1038/ng1296-457

9. Schena M.DNA Microarrays, a practical approach. Oxford University Press.1999;April:110-126.

10.DeRisi JL, Iyer VR, and Brown PO. Exploring the metabolic and genetic control of gene expression on a genomic scale. Science. 1997; 278:680-686.http://dx.doi.org/10.1126/science.278.5338.680

11 Cui D, Zhang L, Yan X, Zhang LX, Xu JR, Guo YH, et al. A microarray-based gastric carcinoma prewarning system. World $J$ Gastroenterol. 2005;11:1273-1282.4.

12.Huang T, Cui D, Lin Q, et al: Expression and its clinical significance of BRCAA1 protein in gastric cancer tissue and various differentiated cell lines. Chin J Gastroenterol. 2007;12:616-619.

13.Liu C. Research and development of nanopharmaceuticals in China. Nano Biomed Eng.2009;1:1-12.http://dx.doi.org/10.5101/nbe.v1i1. p1-12

14.Cui D, Li Q, Huang P, et al. Real time PCR based on fluorescent quenching of mercaptoacetic acid-modified quantum dots for ultrasensitive specific detection of nucleic acids. Nano Biomed Eng 2010;2:45-55.http://dx.doi.org/10.5101/nbe.v2i1.p45-55

15.Li Z, Huang P, Zhang X, et al: RGD-conjugated dendrimer-modified godl nanorods for in vivo tumor targeting and photothermal therapy. Molecular Pharmaceutics. 2010;7:94-104.http://dx.doi.org/10.1021/ mp9001415

16.Huang P, Bao L, Zhang C, Lin J, Luo T, Yang DP, et al. Folic acidconjugated Silica-modified gold nanorods for X-ray/CT imagingguided dual-mode radiation and photo-thermal therapy. Biomaterials. 2011;32:9796-9809.http://dx.doi.org/10.1016/j.biomaterials 2011.08.086

17. Huang P, Li ZM, Lin J, Yang DP, Gao G, Xu C, et al Photosensitizer-conjugated magnetic nanoparticles for in vivo simultaneous magnetofluorescent imaging and targeting therapy. Biomaterials. 2011;32:3447-3458.http://dx.doi.org/10.1016/j. 
http://nanobe.org

biomaterials.2011.01.032

18.Chen L, Bao CC, Yang H, Li D, Lei C, Wang T, et al. A prototype of giant magnetoimpedance-based biosensing system for targeted detection of gastric cancer cells. Biosensors and Bioelectronics. 2011; 26:3246-3253.http://dx.doi.org/10.1016/j.bios.2010.12.034

19. He M, Huang P, Zhang CL, Chen F, Wang C, Ma JB, et al. A general strategy for the synthesis of upconversion rare earth fluoride nanocrystals via a novel OA/ionic liquid two-phase system. Chem. Comm.2011;47(33):9510-9512.http://dx.doi.org/10.1039/ c1cc12886h

20.He M, Huang P, Zhang CL, Hu HY, Bao CC., Gao G, et al. Dual phase-controlled synthesis of uniform lanthanide-doped NaGdF4 upconversion nanocrystals via an OA/ionic liquid two-phase system for in vivo dual-modality imaging. Advanced Functional Materials. 2011. DOI: $10.1002 /$ adfm. 201101040

21.Huang P, Bao L, Zhang C. L, Lin J, Luo T, Gao B, et al. AcidConjugated Silica-Modified Gold Nanorods: Enhancement of Cell Radiation Sensitivity, Photo-Thermal Therapy, and Bio-Imaging. Nanoscale. 2011;3(9):3623-3626.http://dx.doi.org/ $10.1039 / \mathrm{c} 1 \mathrm{nr} 10586 \mathrm{~h}$

22..Zhang F, Braun GB, Pallaoro A, Zhang Y, Shi Y, Cui DX, et al. Mesoporous Multifunctional Upconversion Luminescent and Magnetic "Nanorattle" Materials for Targeted Chemotherapy. Nano Letters. 2011.doi.org/10.1021/nl202949y.

23.Ming SC. Cellular and molecular pathology of gastric carcinoma and precursor lesions: A critical review. Gastric Cancer. 1998;(1):31-50. http://dx.doi.org/10.1007/s101200050053

24.Zhang J, Zhan N, Dong W. Altered expression of selenium-binding protein 1 in gastric carcinoma and precursor lesions. Medical Oncology. 2011;28:951-957.http://dx.doi.org/10.1007/s12032-0109564-6

25.Gaasenbeek M, Mesirov JP, Coller H, et al. Molecular classification of cancer: Class discovery and class predication by gene expression monitoring. Science.1999;286(2):531-537.

26. Howe JR, Mitros FA, Summers RW . The risk of gastrointestinal carcinoma in familial juvenile polyposis. Ann Surg Oncol. 1998, 5(8):751-756.http://dx.doi.org/10.1007/BF02303487

27.Petersson F, Borch K, Franzen LE. Prevalence of subtypes of intestinal metaplasia in the general population and in patients with autoimmune chronic atrophic gastritis. Scand J Gastroenterol. 2002;37(3):262-266.http://dx.doi.org/10.1080/003655202317284156

28.El-Zimaity HM, Ota H, Graham DY, et al. Patterns of gastric atrophy in intestinal type gastric carcinoma. Cancer. 2002; 94(5):1428-1436. http://dx.doi.org/10.1002/cncr.10375

29.Asaka M, Sugiyama T, Nobuta A, et al. Atrophic gastritis and intestinal metaplasia in Japan: results of a large multicenter study. Helicobacter. 2001;6(4):294-299.http://dx.doi.org/10.1046/j.15235378.2001.00042.x

30.Meining A, Morgner A, Miehlke S, et al. Atrophy-metaplasiadysplasia-carcinoma sequence in the stomach: a reality or merely an hypothesis? Best Pract Res Clin Gastroenterol. 2001;15(6):983-998. http://dx.doi.org/10.1053/bega.2001.0253

31.Sande N, Nikulin M, Nilsson I, et al. Increased risk of developing atrophic gastritis in patients infected with CagA + Helicobacter pylori. Scand J Gastroenterol. 2001;36(9):928-933. http://dx.doi.org/10.1080/003655201750305431

32.Sipponen P. Gastric cancer: pathogenesis, risks, and prevention. $J$ Gastroenterol. 2002;37 (Suppl) 13:39-44

33.Oda T, Murakami K, Nishizono A, et al. Long-term Helicobacter pylori infection in Japanese monkeys induces atrophic gastritis and accumulation of mutations in the p53 tumor suppressor gene. Helicobacter.2002;7(3):143-151.http://dx.doi.org/10.1046/j.15235378.2002.00074.x
34. Yao XX, Yin L, Sun ZC. The expression of hTERT mRNA and cellular immunity in gastric cancer and precancerosis. World $J$ Gastroenterol. 2002;8(4):586-590.

35.Nakamura M, Haruma K, Kamada T, et al. Cigarette smoking promotes atrophic gastritis in Helicobacter pylori-positive subjects. Dig Dis Sci. 2002;47(3):675-681.http://dx.doi.org/10.1023/ A:1017901110580

36.Broutet N, Moran A, Hynes S, et al. Lewis antigen expression and mother pathogenic factors in the presence of atrophic chronic gastritis in a European population. J Infect Dis. 2002;185(4):503512.http://dx.doi.org/10.1086/339016

37.StepanovIu M, HrytsenkoII. Role of estrogen receptors in apoptosis and mitotic disorders in patients with atrophic gastritis presenting with precancerous changes of the gastric mucosa. Lik Sprava. 2001;8 (3):30-33

38. Yang SM, Fang DC, Luo YH, et al. Alterations of telomerase activity and terminal restriction fragment in gastric cancer and its premalignant lesions. J Gastroenterol Hepatol. 2001;16(8):876-882. http://dx.doi.org/10.1046/j.1440-1746.2001.02540.x

39.Dawsey SM, Mark SD, Taylor PR, et al. Gastric cancer and H.pylori. Gut.2002;51(3):457-458.http://dx.doi.org/10.1136/gut.51.3.457

40.Honda S., Fujioka T, Tokieda M., et al. Development of Helicobacter pylori-induced gastric carcinoma in Mongolian gerbils. Cancer Research. 1998; 58(19): 4255-4259.

41.Si J, Zhou W, Wu J, Cao Q, Xiang Z, Jiang L, et al. Establishment of an animal model of chronic atrophic gastritis and a study on the factors inducing atrophy. Chin Med J (Engl). 2001;114(12):13231325.

42.Sugiyama T, Hige S, Asaka M. Development of an H.pylori infected animal model and gastric cancer : recent progress and issues. J Gastroenterol. 2002; Suppl.13;37:6-9. http://dx.doi.org/10.1007/ BF02990092

43.Annibale B, Negrini R, Caruana P, Lahner E,Grossi C,Bordi C,et al Two-thirds of atrophic body gastritis patients have evidence of Helicobacter pylori infection. Helicobacter. 2001;6(3): 225-233. http://dx.doi.org/10.1046/j.1083-4389.2001.00032.x

44.Clouston AD. Timely topic: Premalignant lesions associated with adenocarcinoma of the upper gastrointestinal tract. Pathology. 2001; 33 (3):271-277.http://dx.doi.org/10.1080/00313020120070830

45.Recavarren AR, Recavarren AS. Chronic atrophic gastritis: pathogenic mechanisms due to cellular hypersensitivity. Rev Gastroenterol Peru. 2002;22(3):199-205.

46. Megraud F, Broutet N, O’Morain C, Sipponen, P.; Price, A.; Malfertheiner, P.; et al. Risk factors for atrophic chronic gastritis in a European population: results of the Eurohepygast study. Gut. 2002; 50(6):779-785.http://dx.doi.org/10.1136/gut.50.6.779

47.Kokkola A, Sipponen P, Rautelin H, Harkonen M, Kosunen TU, Haapiainen R,et al. The effect of Helicobacter pylori eradication on the natural course of atrophic gastritis with dysplasia. Aliment Pharmacol Ther. 2002;16(3):515-520.http://dx.doi.org/10.1046/ j.1365-2036.2002.01214.x

49.Hunt RH, Fallone C, Van Zanten SV, Sherman P, Flook N, Smaill F, et al. Risks and benefits of Helicobacter pylori eradication: current status. Can J Gastroenterol. 2002;16(1):57-62.

50.Tsai CJ, Tibshirani R, De Arruda SM, Yang SF, Parsonnet J. Genomic analysis of gastric cancer in H.pylori infected patients. Gastroenterology. 2002; 22(4): S1155.

Copyright:(c) $2011 \mathrm{~J} . \mathrm{Xu}$, et al. This is an open-access article distributed under the terms of the Creative Commons Attribution License, which permits unrestricted use, distribution, and reproduction in any medium, provided the original author and source are credited. 